\title{
miR-29 family regulates the puberty onset mediated by a novel Gnrh1 transcription factor TBX21
}

\author{
Xiaoning Li1', Junhua Xiao1, Yating Fan1, Kan Yang1, Kai Li1, Xin Wang1, Yanhua Lu² and Yuxun Zhou1,3 \\ ${ }^{1}$ College of Chemistry, Chemical Engineering \& Biotechnology, Donghua University, Shanghai, China \\ 2State Key Laboratory of Bioreactor Engineering, East China University of Science and Technology, Shanghai, China \\ ${ }^{3}$ Human Phenome Institute, Fudan University, Shanghai, China
}

Correspondence should be addressed to Y Zhou: zhouyuxun@dhu.edu.cn

\begin{abstract}
Gonadotropin-releasing hormone $(\mathrm{GnRH})$ is the ultimate signal by which the neuroendocrine system controls the puberty onset and fertility in mammals. The pulsatile release of $\mathrm{GnRH}$ is regulated by numerous extracellular and intracellular factors, including miRNAs. Here, we report a novel regulation mechanism mediated by miR-29 family. We found that the absence of miR-29s resulted in elevated expression of Gnrh1 in GT1-7 cells. Through in silico and wet analysis, we identified Tbx21, a target gene of miR-29, as the main effector. As a transcription activator, TBX21 stimulates the expression of Gnrh1 directly by binding to its promoter region, and indirectly by activating the expression of $D / x 1$, another transcription activator of Gnrh1. Stereotactic brain infusion of miR-29 inhibitor into the hypothalamus caused earlier puberty onset in prepubertal female mice than that of intact controls. The female mice with ectopic expression of Tbx21 in the hypothalamus were affected in both puberty onset and fertility, as they had higher level of serum LH and FSH, larger litter size but steeper decline of fertility compared with those of controls. Our results revealed that miR-29-3p and its target $T b \times 21$ played a role in regulating the mammalian puberty onset and reproduction by modulating the Gnrh1 expression.
\end{abstract}
Key Words
- puberty onset
- GnRH
- miR-29 family
- Tbx21
- GT1-7 cells
- CRISPR/Cas9
- stereotactic brain infusions
- female mouse

\section{Introduction}

Puberty is the attainment of fertility, a process encompassing morphological, physiological and behavioral development. In neuroendocrineterms, puberty onset is the result of the reactivation of hypothalamuspituitary-gonad (HPG) axis, symbolized by the pulsatile release of gonadotropin-releasing hormone (GnRH) (Ebling 2005). GnRH is a peptide hormone composed of ten amino acids (pGlu-His-Trp-Ser-Tyr-Gly-Leu-ArgPro-Gly-NH2) (Lee et al. 2008) and represents the final output of neuroendocrine system that regulates sexual development and reproductive function (Herbison 2016). A great number of extracellular and intracellular factors have been reported to regulate the Gnrh1 expression (Lee et al. 2008, Herbison 2016, Avendano et al. 2017), among which, miRNAs have received increasing attention (Messina et al. 2016). miRNAs are genome encoded, noncoding, 21 nucleotide-long RNA molecules which are involved in post-transcriptional regulation of gene expression and control many developmental and cellular processes in eukaryotic organisms (Krol et al. 2010). 
miRNAs are particularly abundant in the brain where they act as 'master regulators' or 'fine-tuners' of gene expression to play regulatory roles ranging from neuronal development to fulfilling function (Saba \& Schratt 2010, Rajman \& Schratt 2017). Although more than 210 miRNAs were detected in the arcuate (ARC) and paraventricular (PVN) nuclei of rat hypothalamus where the puberty onset modulating machinery is located (Amar et al. 2012), only a small portion of them have been proved with direct evidences in regulating the puberty onset of mammals. Deletion of miR-9 and miR-200 resulted in altered GnRH neuron development (Garaffo et al. 2015), miR-200 and miR-155 have been demonstrated to promote the expression of Gnrh1 by inhibiting the repressors of Gnrh1 promoter Zeb1 and Cebpb, respectively (Messina et al. 2016) in mouse GnRH neurons. miR-505-3p was proved to play a role in regulating the puberty onset of female mice (Zhou et al. 2018).

miR-29 family (miR-29s) consists of four members: miR-29a, miR-29b1, miR-29b2 and miR-29c, which have been postulated to potentially regulate more than 4000 gene products. In the central nervous system, miR-29 family is involved in the development of nervous system, the maintenance of mature neuron and the plasticity of nerve cell regulation (Lippi et al. 2011, Annis et al. 2016, Ripa et al. 2017).

In our previous work, we found that the expression levels of miR-29s in mouse hypothalamus gradually increased during the sexual development (Omariba et al. 2018). Similarly, Zhang et al. showed that miR-29a-3p was expressed differentially in the developing hypothalamus of porcine (Zhang et al. 2013a). Messina et al. also found that the expression level of miR-29 family members in mouse GnRH neurons were higher at postnatal day 12 than that at postnatal day 7 , and their abundance was higher in GnRH neuron than that in non-GnRH neurons (Messina et al. 2016). Moreover, mice with brain-specific miR-29 knockdown showed decreased reproductive capacity in males, in contrast with female mice (Takeda $\&$ Tanabe 2016). Turquoise killifish with neuron-specific miR-29 knockdown also showed the phenotype of decreased fertility (Ripa et al. 2017). These collective evidences imply that miR-29s can be an important regulator of puberty onset and reproduction.

GT1-7 cells are immortalized GnRH neurons derived from mouse hypothalamic neurons and provide an ideal model system for studying the regulation of Gnrh1 expression (Keynes et al. 1990). In this study, we generated a miR-29s-knockout GT1-7 cell strain using the CRISPR/Cas9 technology. In miR-29s-knockout GT1-7 cells, the level of Gnrh1 expression increased by two-fold. Tbx21, a target gene of miR-29 family, acts as a transcriptional activator of Gnrh1 in this process, TBX21 also activates the expression of Dlx1, another activator of Gnrh1 promoter. Both inhibition of miR-29s and promotion of Tbx21 in the hypothalamus of prepubertal female mice affects the timing of puberty onset, and some reproductive phenotype could be affected by the ectopic expression of Tbx21 significantly.

\section{Methods}

\section{Construction of vectors}

The plasmid 42230-multi-sgRNAs-miR-29, an all-inone vector targeting four miR-29 family members, was constructed by firstly inserting the $20 \mathrm{bp}$ proto-spacer sequence of miR-29a into the Bbs I site of pX330-U6Chimeric_BB-CBh-hSpCas9 plasmid (Addgene; 42230), and then inserting the sgRNA cassettes targeting miR-29b1, miR-29b2 and miR-29c respectively into the EcoR I site step by step. These sgRNAs were designed for each miRNA according to CRISPR DESIGN (http://crispr.mit.edu/). The sequences were listed in Supplementary Table 1 (see section on supplementary data given at the end of this article). To facilitate the screening for the cells with miR-29 family knockout, we also introduced a cassette of puromycin $\mathrm{N}$-acetyltransferase (PuroR) which was transcribed by its own mouse phosphoglycerate kinase 1 (PGK) promoter at the end of sgRNA cassettes. A 42230-sgRNA-Dlx1 used to generate a Dlx1-knockout cell model was also constructed by using the same method.

\section{Cell culture and transfection}

GT1-7 and N6 cells were cultured in high-glucose DMEM (KeyGENBioTECH, Nangjing, China), containing v/v $10 \%$ FBS (Thermo Fisher Scientific), and $100 \mathrm{U} / \mathrm{mL}$ penicillin- $100 \mu \mathrm{g} / \mathrm{mL}$ streptomycin in a humidified incubator with $5 \% \mathrm{CO}_{2}$ at $37^{\circ} \mathrm{C}$.

Plasmids, miRNA inhibitors (a single-stranded RNA complementary to miR-29a-3p chemically synthesized by Gene Pharma, Shanghai, China) or miRNA mimics (a single-stranded RNA identical to miR-29a-3p chemically synthesized by Gene Pharma) was used in transient transfection following a protocol recommended by the manufacturer of Lipofectamine ${ }^{\mathrm{TM}} 3000$ reagent (ThermoFisher). Cells were seeded into 24 -well plates 1 day prior to transfection at a density of 150,000 cells/well. 
For miR-29 family knockout, $1 \mu \mathrm{g}$ of 42230-multi-sgRNAsmiR-29 plasmid was used. For miR-29 family knockdown, $20 \mathrm{pmol}$ of miR-29a inhibitor was used. For overexpression of Tbx21, $1 \mu \mathrm{g}$ of pCMV6-Tbx21 (OriGene Technologies, Inc., Rockville, MD, USA) was used.

\section{Generation of stable cell lines}

The miR-29 family-deleted GT1-7 cell lines, Dlx1-knockout cell line and $T b \times 21$-overexpressed cell line were generated following the same protocol as following (except for the antibiotics employed for screening according to the antibiotic resistant genes carried by the plasmid): $300 \mathrm{ng} / \mathrm{mL}$ puromycin were added into the culture medium $48 \mathrm{~h}$ after transfection and incubated for additional 4 days before changing the medium into DMEM plus 10\% FBS. After cultivated for another 7 days, colonies were picked and cultivated expansively. To confirm the deletion of miR-29 family in GT1-7 cells, the targeted regions were amplified by PCR using the genomic DNA extracted from the puromycin-resistant clones as template. The primer sequences were listed in Supplementary Table 1. PCR products with correct length were confirmed by Sanger sequencing. Potential off-target sites of all miR-29 sgRNAs were predicted by CRISPR DESIGN, and their off-target effects were examined in top 10 loci of each sgRNA accordingly. These predicted off-target loci were PCR amplified from miR-29-knockout cells and detected by three-round multiplex PCR for genotyping with nextgeneration sequencing (Chen et al. 2016). The primer sequences were listed in Supplementary Table 2.

\section{RNA extraction and quantitative reverse transcription PCR (qRT-PCR)}

Total RNA from miR-29-knockout cell line was extracted using RNAiso Plus (TaKaRaBio Inc.) according to the manufacturer's recommendations. To extract total RNA from hypothalamus, the hypothalamus of mice was taken out and shredded in RNAiso Plus and subsequent steps were the same as that for cells. Genomic DNA was eliminated by DNase I digestion (ThermoFisher), and then the cDNA was synthesized by using Thermo Scientific RevertAid Frist-Strand cDNA Synthesis Kit (ThermoFisher). Specific stem-loop reverse transcription (RT) primers for mature miRNAs were designed respectively, and miR-16-5p was used as the internal control (Tong et al. 2015). The mRNA was reverse transcribed with oligo-dT as primer. Quantitative PCR were carried out on Applied Biosystems 7500 Real-Time PCR system (ThermoFisher) using SYBR
Green SuperRealPreMixPlus (TIANGEN, Beijing, China); all reactions were run in triplicate and no template controls were included for each gene. $2^{-\Delta \Delta C t}$ was used to calculate the fold change of the expression level of a gene between the test and control samples. The primers for each gene were listed in Supplementary Table 1.

\section{Western blot}

The cells were seeded and cultured in a six-well plate. After removal of the media, the cells were washed twice with icecold PBS, and then lysed using Nucleoprotein Extraction Kit (Sangon Biotech, Shanghai, China) according to the manufacturer's recommendations. The samples were boiled for $5 \mathrm{~min}$ before they were loaded onto SDS-PAGE; electrophoresis was run at $80 \mathrm{~V}$ for $30 \mathrm{~min}$ in the $4 \%$ stacking gel and at $120 \mathrm{~V}$ for $60 \mathrm{~min}$ in $10 \%$ separation gel. And then the proteins were transferred onto $0.45 \mu \mathrm{m}$ PVDF membrane (Merck Millipore) at $300 \mathrm{~mA}$ for $100 \mathrm{~min}$. The membrane was blocked at room temperature for $1 \mathrm{~h}$ with blocking solution (w/v 5\% BSA in TBST) and incubated overnight at $4^{\circ} \mathrm{C}$ with the appropriate primary antibody diluted in blocking buffer (mouse monoclonal anti-PCNA, D190751, 1:1,000 (Sangon Biotech, Shanghai, China); mouse monoclonal anti-Tbx21, sc-21749, 1:5000 (Santa Cruz Biotechnology)). The membranes were washed three times with TBST before being incubated with HRP-conjugated secondary antibody (anti-mouse IgG; Beyotime, Shanghai, China) 1:1000 for anti-PCNA, 1:5000 for anti-Tbx21 diluted in blocking buffer for $1 \mathrm{~h}$ at room temperature. The ECL detection kit was used for visualization of PCNA (Thermo Fisher) and SuperSignal West Femto Trial Kit was used for that of TBX21 (Thermo Fisher). Immunoblots were scanned and analyzed using Image Lab software (Bio-Rad).

\section{Dual-luciferase gene reporter assay}

The full-length of WT sequence of the 3'UTR of Tbx21 containing miR-29-binding sites was amplified by PCR and cloned into the psiCHECK-2 vector (Promega Corp.). The plasmid was named Tbx21-3'UTR-WT. The mutant Tbx21-3'UTR-MU was constructed by QuickMutation ${ }^{\mathrm{TM}}$ Site-Directed Mutagenesis Kit (Beyotime) according to the manufacturer's instructions. For the detection of dual-luciferase activity, GT1-7 cells were co-transfected with miR-29 mimic $(20 \mathrm{mM})$ or scramble $(20 \mathrm{mM})$ and Tbx21-3'UTR-WT (500ng) or Tbx21-3'UTR-MU (500 ng). Forty-eight hours later, cells were lysed using Reporter Lysis Buffer, and the activities of Renilla and Firefly 
luciferase were analyzed respectively, using a DualLuciferase Reporter Gene Assay Kit (Beyotime) according to the manufacturer's recommendations.

\section{Chromatin immunoprecipitation assays}

The chromatin isolation and enzymatic digestion of GT1-7 cells was performed using the Pierce Chromatin Prep Module Kit (ThermoFisher) following the manufacturer's instructions. Then, chromatin immunoprecipitation (ChIP) was carried out by using the Pierce Agarose ChIP Kit (ThermoFisher). After shearing by MNase, proteinbound DNA was immunoprecipitated at $4^{\circ} \mathrm{C}$ overnight using $5 \mu$ g of a mouse monoclonal anti-Tbx21 antibody or goat IgG control. ChIP-DNA fragments were analyzed using quantitative PCR. The primers used for ChIP was designed according to the prediction of JASPAR, a database of transcription factor-binding profiles (http://jaspar. genereg.net). The productions of each pair of primers covered two to four binding sites of TBX21 with score higher than 5.5. The primers for each gene were listed in Supplementary Table 1 .

\section{Animals}

All animal procedures were approved by the Animal Ethics Committee of Donghua University, and all experiments were conducted in strict compliance with the National Institutes of Health Guide for the Use of Laboratory Animals. C57BL/6 mice were group-housed under specific pathogen-free conditions in a temperature-controlled room $\left(21-22^{\circ} \mathrm{C}\right)$ with a 12 -h light-darkness cycle and ad libitum access to food and water. Female mice were weighed at postnatal day (PND) 1, the day of birth and weaned at PND 20. Vaginal opening (VO) was monitored daily from the time of weaning. The vaginal smears of females were taken daily and analyzed under an inverted microscope to identify the specific day of the estrous cycle (Byers et al. 2012). The fertility indices of 3-monthold females were calculated from the size of litters and the frequency of fertility during a 60-day mating with WT male.

\section{Stereotactic brain infusions}

Female mice were placed in a stereotaxic frame (RWD Life Science, Shenzhen, China) under anesthesia (amobarbital sodium), and a burr hole was drilled at the bregma. A $10 \mu \mathrm{L}$ Hamilton syringe was slowly inserted into the bottom of the left lateral ventricle $(5.75 \mathrm{~mm}$ deep relative to the dura) and $1 \mu \mathrm{L}$ of the different treatment solutions
(antagomiR-NC, Gene Pharma, $50 \mu \mathrm{mol} / \mathrm{L}$; antagomiR-29a, Gene Pharma, $50 \mu \mathrm{mol} / \mathrm{L}$; lenti-null-P2A-eGFP, a lentivirus for control, $10^{8} \mathrm{TU} / \mathrm{mL}$; lenti-Tbx21-P2A-eGFP, a lentivirus for $\mathrm{Tb} \times 21$ overexpression, $10^{8} \mathrm{TU} / \mathrm{mL}$ ) was injected using an infusion pump (KD Scientific, MA, USA) over $20 \mathrm{~min}$. Mice were randomly assigned for injection. Animals were subjected to intracranial surgery at PND15.

\section{Tissue preparation and digital image acquisition}

Mice were anesthetized with amobarbital sodium and perfused transcardially with $30 \mathrm{~mL}$ of saline, followed by $20 \mathrm{~mL}$ of $\mathrm{w} / \mathrm{v} 4 \%$ PFA, $\mathrm{pH}$ 7.4. Brains were collected, post fixed in the same fixative for $24 \mathrm{~h}$ at $4^{\circ} \mathrm{C}$, dehydrated in $\mathrm{w} / \mathrm{v}$ $20 \%$ sucrose for $24 \mathrm{~h}$ at $4^{\circ} \mathrm{C}$, followed by soaking in w/v $30 \%$ sucrose for $24 \mathrm{~h}$ at $4^{\circ} \mathrm{C}$. The brains were embedded in OCT embedding medium (Tissue-Tek, Sakura Finetek USA, Inc., CA, USA), frozen at $-20^{\circ} \mathrm{C}$ and cryosectioned (ThermoFisher) at $10 \mu \mathrm{m}$. Sections were analyzed using fluorescence microscope.

\section{Immunofluorescence assay}

The brain of mouse was taken as mentioned above. Brains were cut and divided in three sets of coronal sections $(30 \mu \mathrm{m})$ in a freezing microtome. The slides were washed for $15 \mathrm{~min}$ with $0.01 \mathrm{M}$ PBS, blocked for $1 \mathrm{~h}$ with 5\% BSA in PBS and incubated with appropriate antibodies (diluted 1:100 in 0.01 M PBS with 5\% BSA; rabbit polyclonal anti-GnRH, NB300-506, Novus Biologicals; mouse monoclonal anti-Tbx21, sc-21749, Santa Cruz Biotechnology) for $48 \mathrm{~h}$. After washing, the sections were incubated with m-IgGk BP-CFL 555 (sc-516177, Santa Cruz Biotechnology) and Alexa Fluor 488-labeled Goat Anti-Rabbit IgG (Beyotime) for $2 \mathrm{~h}(1: 100$ in $1 \%$ PBS with 5\% BSA). After incubation, the slides were washed with PBS and treated with 4,6'-diamidino-2-phenylindole (DAPI) for $10 \mathrm{~min}$, rinsed and covered with fluorescent mounting medium.

\section{Hormone assays}

Serum hormone levels were measured by ELISA. Blood of mice in the estrous was drawn from the orbital sinus, placed for $30 \mathrm{~min}$ at room temperature and centrifuged at $10,000 \mathrm{~g}$ for $15 \mathrm{~min}$ at $4^{\circ} \mathrm{C}$. The serum was collected and stored at $-80^{\circ} \mathrm{C}$ until assayed. $\mathrm{LH}$ and FSH were measured using a colorimetric ELISA kit (Elabscience Biotechnology Co., Ltd, Wuhan, China) following the manufacturer's instructions. 


\section{Statistical analyses}

All data analyses were performed using Prism 5 (Graphpad software). All values shown are means \pm s.E.M. The method used, the number of biologically independent experiments, $P$ values were indicated in the main text or in the figure legends.

\section{Results}

\section{The construction of miR-29 family knockout GT1-7 cell line}

The expression trend of miR-29s in mouse hypothalamus from PND5 to PND 30 was verified by qRT-PCR (Fig. 1A). The expression levels of mature miR-29s gradually increase during this period. As shown in Fig. 1B, we constructed a plasmid which carried the expression cassettes of a Cas9 nuclease, four sgRNAs targeting the locus of each miR-29 member and a puromycin resistance gene used for screening of stable miRNA-knockout cells. After transfection and puromycin treatment, clones derived from the single cell were tested. The expression of miR-29s was extinguished almost completely in one of the puromycin resistance clones (Fig. 1C), and its Sanger sequencing results displayed a homozygous large fragment substitution between sgRNA-miR29a1 and sgRNA-miR29b1 (Fig. 1D and Supplementary Fig. 1), as well as a heterozygous inversion between sgRNA-miR29b2 and sgRNA-miR29c at one allele, and two small deletions at the other allele (Fig. 1F and Supplementary Fig. 1).

\section{miR-29s are regulatory factors of the expression of Gnrh1 and its transcription factor DIx1}

Eight puberty-related genes (Luque et al. 2007) expressed in GT1-7, including Gnrh1, Kiss1, Tac2, Gpr54, Igf1r, Irs 1, Lepr and Npy4r were tested and only the expression of Gnrh1 showed significant difference in the miR-29sknockout cells (Fig. 2A). In order to figure out whether

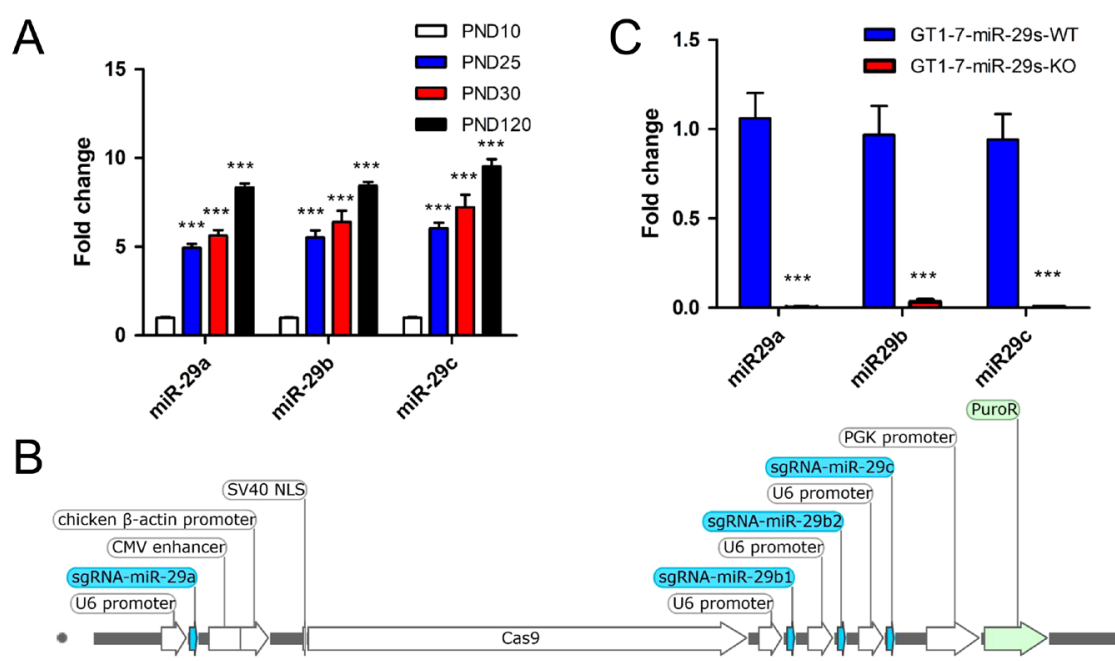

D miR-29s -WT AAGCTTCTTCAGGAAGCTGGTTTCATATGGTGGTTTAGATTTAAATAGTGATTGTCTAGCACCATTTG... 芒 miR-29

穵 miR-29s -WT ...GTTCAGAGTCAATAGAATTTTCTAGCACCATCTGAAATCGGTTATAATGATTGGGGAAGAGCACCG miR-29s -Ko ...TGCCCGAAGGACCGCGCACCTGGTGCATGACCCGCAAGCCCGGTCATTGGGGAAGAGCACCG

E miR-29s -Wt tCTGCTTTCtTCAGTGAGATCCTCTTCTTCTGGAAGCTGGTTTCACATGGTGGCTTAGATTTTTCCAT... -

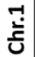
miR-29s -KO TCTGCTTTCTTCAGTGAGATCCTCTTCACATCATAACCGATTTCAAATGGTGCTAGACAAAAACAGAC.. miR-29s-WT ...CTGGTGTTCAGAGTCTGTTTTTGTCTAGCACCATTTGAAATCGGTTATGATGTAGGGGGAGAGCA miR-29s -Ko ...AGATACAAAGATGGAAAAATCTAAGCCACCATGTGAAACCAGCTTCCAGAAAGGGGGAGAGCA

F miR-29s -WT TCAGTGAGATCCTCTTCTTCTGGAAGCTGGTTTCACATGGTGGCTTAGATTTTTCCATCTTTGTATCTAG 논. mirmiR-29s -KO TCAGTGAGATCCTCTTCGCTTCACTCTCCC CATCTCCCCCCCCTCCCCACCCCTGGAAGC-TGTATCTAG miR-29s - WT TTTTTGTCTAGCACCATTTGAAATCGGTTATGATGTAGGGGGAAGAGCACCAGCCTCAGAACCTTGTG

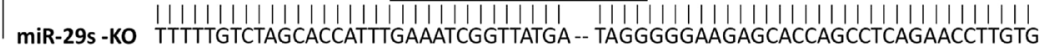

\section{Figure 1}

The construction of miR-29 family knockout GT1-7 cell line. (A) The expression of miR-29s from infants to adults in mouse hypothalamus detected by qRT-PCR. One-way ANOVA post hoc Dunnett's test, $n=6$ mice per group, compared with PND10 all $P<0.0001$. (B) Schematics of miR-29s-knockout plasmid, PuroR: puromycin resistance gene. (C) The expression of miR-29s in stable miR-29s-knockout cell GT1-7-miR-29s KO. Unpaired two-tailed Student's $t$-test, $n=8$ per group, $P_{(\text {mir-29a) }}<0.0001, P_{\text {(mir-29b) }}<0.0001$, $P_{(\text {miR-29c) }}<0.0001$. (D) The genotype of miR-29a and miR-29b1 locus. The underlined bases are the sgRNAs recognition sites. ( $E$ and $F$ ) The genotype of miR-29b2 and miR-29c locus. The underlined bases are the sgRNAs recognition sites. $\star \star \star P<0.001$. A full colour version of this figure is available at https://doi.org/10.1530/JOE-19-0082. 


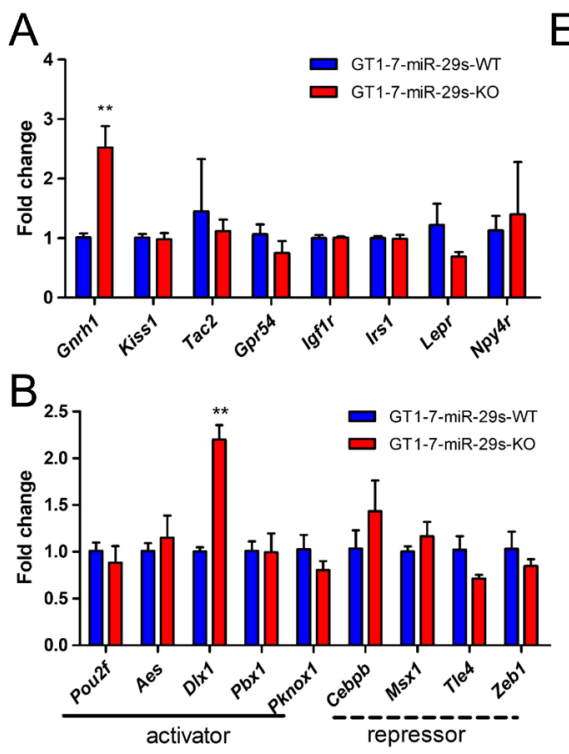

$\mathrm{E}$
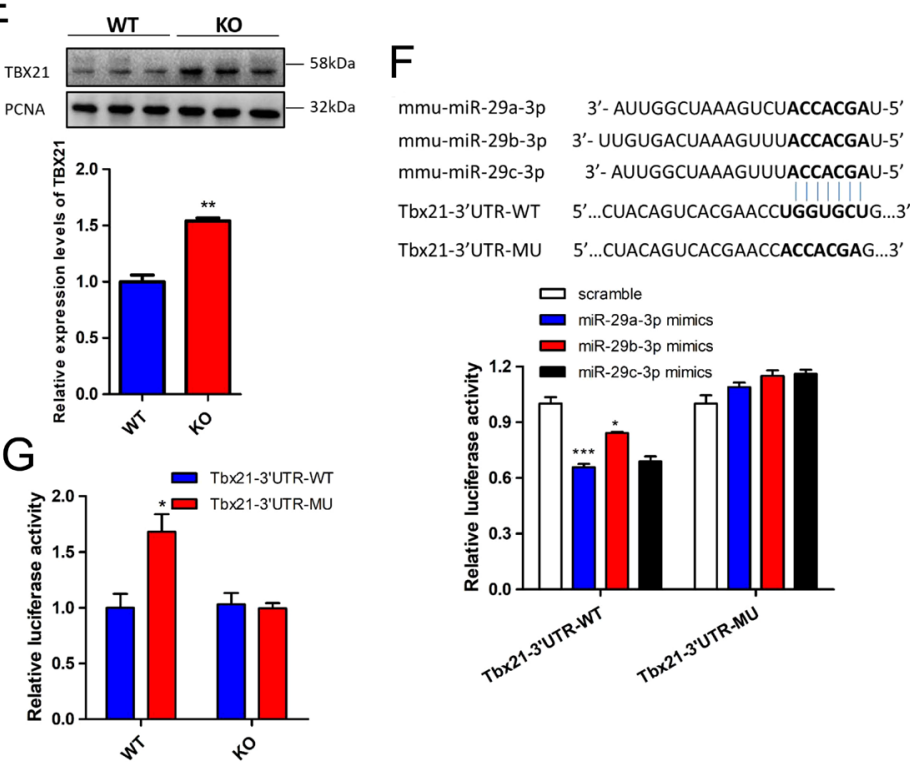

Tbx21-3'UTR-MU 5'...CUACAGUCACGAACCACCACGAG...3'
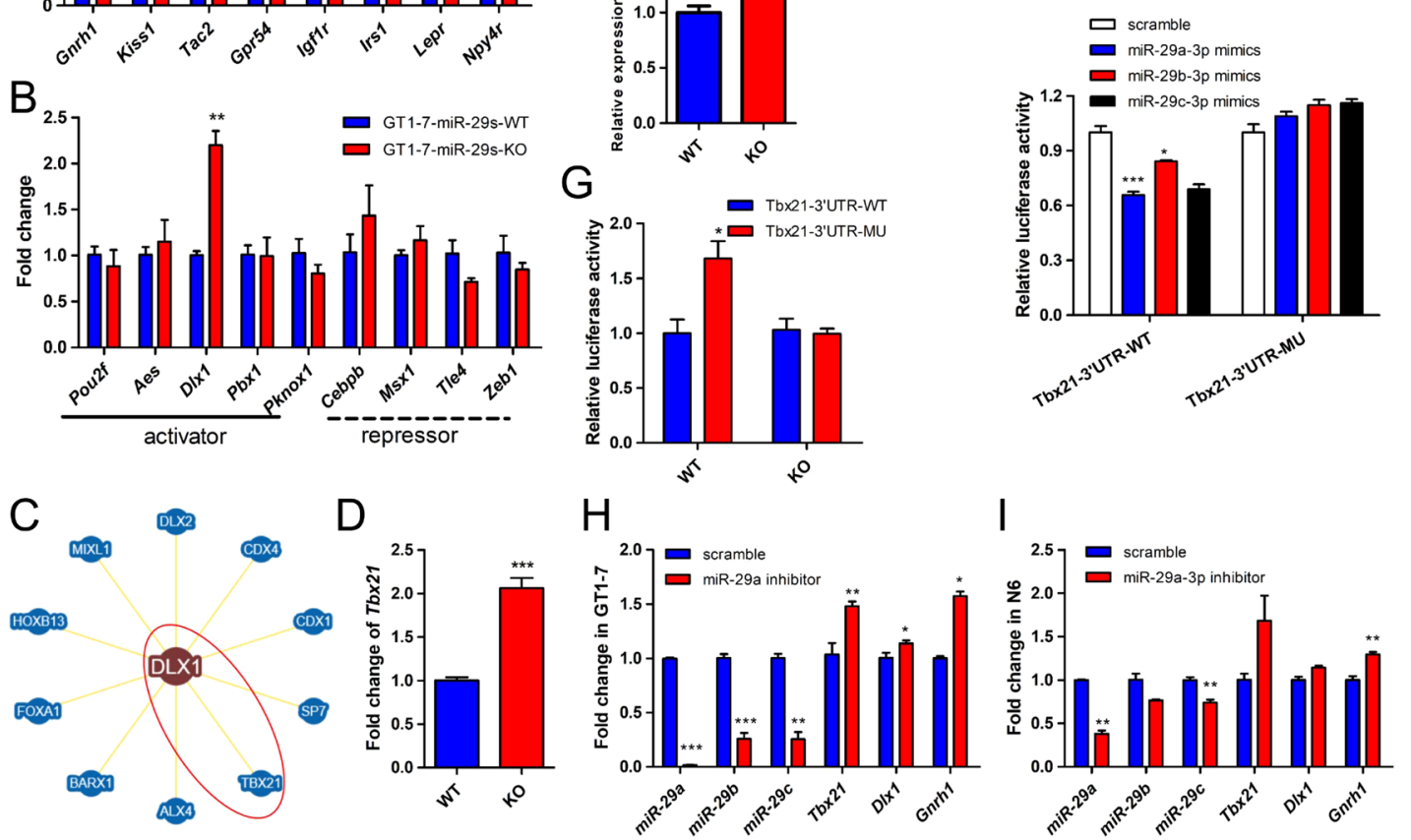

\section{Figure 2}

The relationship between miR-29s and Tbx21, Tbx21 and the Gnrh1 promoter, Tbx21 and the Gnrh1 activator D/x1. (A) A screen of puberty-related genes influenced by miR-29s knockout. Unpaired two-tailed Student's $t$-test, $n=5-6$ per group, $P_{(\mathrm{Gnrh} 1)}=0.0021, P_{(\mathrm{Kiss} 1)}=0.8147, P_{(\mathrm{Tac2})}=0.7275, P_{(\mathrm{Gpr} 54)}=0.2502$, $P_{(\mathrm{lgf1r})}=0.9384, P_{\text {(Irs1) }}=0.8523, P_{\text {(Lepr) }}=0.1739, P_{\text {(Npy4r) }}=0.7556$. (B) A screen of Gnrh1 transcription factors influenced by miR-29s knockout. Unpaired two-tailed Student's $t$-test, $n=3$ per group, $P_{(\text {Pouz } 2)}=0.5587, P_{(\mathrm{Aes})}=0.5960, P_{(\mathrm{D} \mid \times 1)}=0.0018, P_{(\mathrm{Pbx} \times 1)}=0.9506, P_{(\mathrm{Pknox} 1)}=0.2877, P_{(\mathrm{Cebpb})}=0.3554, P_{(\mathrm{Ms} \times 1)}=0.3801$, $P_{\text {(Tle4) }}=0.1123, P_{\text {(Zeb1) }}=0.4109$. (C) The interacting genes of $D / x 1$ analyzed by BioGRID. (D and E) The mRNA and protein level of Tbx21 expression in GT1-7-miR-29s-KO. Unpaired two-tailed Student's t-test, for qPCR, $n=5$ per group, $P_{(\text {mRNA }}<0.0001$; for Western blot, $n=3$ per group, $P_{(\text {protein })}=0.0011$. (F) The interaction between miR-29s and Tbx21 mRNA 3'UTR in GT1-7 detected by dual-luciferase reporter assay. Unpaired two-tailed Student's $t$-test, $n=6$ per group for Tbx21-3'UTR-WT, $P_{(\text {miR-29a) }}=0.0010, P_{(\text {miR-29b) }}=0.0117, P_{(\text {miR-29c) }}=0.0023$; for Tbx21-3'UTR-MU, $P_{(\text {miR-29a) }}=0.1152, P_{(\text {miR-29b) }}=0.0945$, $P_{(\text {miR-29c) }}=0.0776$. (G) The relative luciferase activity of dual-luciferase reporter in GT1-7 with or without miR-29s. Unpaired two-tailed Student's $t$-test, $n=6$ per group, for GT1-7-miR-29s-WT (WT), $P=0.0281$; for GT1-7-miR-29s-KO (KO), $P=0.9468$. (H) The verification of miR-29s effect on Tbx21, D/x1 and Gnrh1 by miR-29s knockdown in GT1-7 cell. Unpaired two-tailed Student's $t$-test, $n=6$ per group, $P_{\text {(mir-29a) }}<0.0001, P_{\text {(mir-29b) }}=0.0007, P_{\text {(mir-29c) }}=0.0011$, $P_{(\mathrm{Tb} \times 21)}=0.0018, P_{(\mathrm{D} \mid \times 1)}=0.0271, P_{(\mathrm{Gnrh} 1)}=0.0403$. (I) The verification of miR-29s effect on Tbx21,D/x1 and Gnrh1 by miR-29s knockdown in N6 cell. Unpaired two-tailed Student's $t$-test, $n=6$ per group, $P_{(\text {miR-29a) }}=0.0051, P_{(\text {miR-29b) }}=0.0687, P_{(\text {miR-29c) }}=0.0042, P_{(\text {tbx21) }}=0.0930, P_{(\mathrm{Dl} \times 1)}=0.0895, P_{(\text {Gnrrh1) }}=0.0099 . * P<0.05$, $* \star P<0.01,{ }^{* \star *} P<0.001$. A full colour version of this figure is available at https://doi.org/10.1530/JOE-19-0082.

a single miR-29 had played the predominant role in this process or not, each of the four members of miR-29s were knocked out individually in GT1-7 cells using similar method, but the significant change in Gnrh1 expression was not observed in any of these cells (Supplementary Fig. 2), which implied that miR-29s functioned in a redundant way here.

Since the 3' untranslated region (3'UTR) of Gnrh1 mRNA had no binding sites for miR-29s, we speculated that some transcription factor might have played a role in this modulation. The expression pattern of nine transcription factors of Gnrh1 (Messina et al. 2016) were checked; and among the five activators and four repressors, one transcription activator, Distal-less homeobox-1 (Dlx1), manifested significant increase in the expression level in the absence of miR-29s (Fig. 2B), while Dlx1 was not the target of miR-29s either.

The interactive partners of Dlx 1 were searched on BioGRID (https://thebiogrid.org), counting on some targets of miR-29s playing the role (Fig. 2C). TBX21 was screened out as the working partner of DLX1 by the mammalian two-hybrid system (Ravasi et al. 2010), 
its coding gene $T b \times 21$ was targeted by all of the three members of miR-29 family (Steiner et al. 2011), and it has binding sites in the promoter regions of Dlx1 and Gnrh1 predicted by JASPAR. The expression of Tbx21 in the miR-29s-null GT1-7 cell was checked, and the accumulation of both the mRNA and protein of $T b \times 21$ increased as expected (Fig. 2D and E). Dual-luciferase gene reporter assay was carried out to verify the interaction between miR-29-3p and Tbx21 in GT1-7 cells. The data showed miR-29-3p could bind to 3' UTR of Tbx21 mRNA and reduce the amount of luciferase (Fig. 2F). On the other hand, the relative luciferase activity was recovered due to the mutations of the miR-29-binding site on Tbx21 3'UTR in WT cells. While in the miR-29s-null cells, the luciferase activity was no longer affected by the form of miR-29-binding site (Fig. 2G).

The off-target loci of the four sgRNAs were predicted using CRISPR DESIGN algorithm (http://crispr.mit.edu/), and the top 10 off-target suspects for each locus were PCR amplified and sequenced by next-generation sequencing accordingly. At least in these 40 loci, no off-target effect was detected (Supplementary Table 3).

To further ensure the consequences caused by miR-29s reduction, both GT1-7 and N6 cells, another GnRH-expressing hypothalamic neuronal cell model (Belsham et al. 2004), were transfected with miR-29a inhibitor. After $48 \mathrm{~h}$ of transfection, the accumulation of all miR-29 members dropped and the Tbx21 expression increased (Fig. 2H and I). We then treated GT1-7 cells with miR-29 mimics to test whether the miR-29 overexpression interfered with the Gnrh1 expression. The results showed that the supply of any combination of miR-29 family members could not cause significant differences in the amount of Gnrh1 mRNA (Supplementary Fig. 3).

\section{TBX21 is a novel transcription factor of Gnrh1}

Tbx21 is a member of Tbr1 subfamily of T-box transcription factor genes that mainly regulate brain development. The expression of $T b \times 21$ was detected in the olfactory bulbs (OBs) where GnRH neurons originated (Mihalas \& Hevner 2017). The Allen Human Brain Atlas (http:// portal.brain-map.org/) also showed that the region where the TBX21 expressed largely overlapped with that of GNRH1 and DLX1 in the hypothalamus. Meanwhile, the RNA-seq data of GT1-7 and GN11, a cell strain derived from immature, migratory GnRH neurons, measured by Huang et al., displayed the expression level of $T b \times 21$ was higher in the GT1-7 than that in the GN11 cells (Huang et al. 2016), implying $T b \times 21$ had similar expression trend with
Gnrh1 (Supplementary Table 4). Taken together, these data support the hypothesis that the increased Gnrh1 and Dlx1 in the absence of miR-29s could be mediated by Tbx21. Immunofluorescence colocalization results showed that Tbx21 was co-expressed with Gnrh1 in the medial eminence (ME) where GnRH neuron distributed (Fig. 3A). Consistent with Gnrh1, the expression level of $T b \times 21$ rose continuously during sexual development. Unexpectedly, the expression of Dlx 1 decreased from infancy to puberty but upregulated from puberty to adulthood (Fig. 3B). Then, the effect of Tbx21 on Gnrh1 and Dlx1 was studied in vitro. The expression of both Gnrh1 and Dlx1 were promoted by Tbx21 overexpression in GT1-7 and N6 cells (Fig. 3C, D and E). In a Tbx21 stably overexpressed GT1-7 cell line, the Gnrh1 expression was obviously enhanced (Fig. 3C and F). As TBX21 was predicted to bind to the promoters of both Gnrh1 and Dlx1 and function as a transcription activator, a ChIP assay was carried out and DNA fragments with predicted binding sites upstream of Gnrh1 and Dlx1 were significantly enriched( Fig. 3G and H).

Since DLX1 is a transcription activator of Gnrh1, and predicted to interact with TBX21, it is rational to propose that TBX21 may probably form a complex with DLX1 when binding to the Gnrh1 promoter region, besides binding to it directly. Therefore, we constructed a Dxl1knockout GT1-7 cell model, in which frame shift mutation existed in the Dlx1-coding region (Fig. 3I), resulting in a nonfunctional product of $D l x 1$ with the deletion of DNA-binding domain. However, in this Dlx1-null cell line, the activation of Gnrh1 expression caused by $T b \times 21$ overexpression was not impaired (Fig. 3J), which suggests that DLX1 may not be essential for TBX21 binding to the Gnrh1 promoter.

\section{Repression of miR-29a promotes the puberty onset}

To assess the functional involvement of miR-29 family members in the puberty-onset regulation, we performed stereotactic brain infusions of antagomiR-29a in hypothalamus of prepubertal female mice. AntagomiR-29a is a cholesterol-conjugated and cy3-labeled singlestranded RNA analogue complementary to miR-29a-3p, which prevents miR-29-3p from attaching to the $3^{\prime} \mathrm{UTR}$ of its target genes, scrambled-sequence antagomiR-NC was used as control. Similar to the miR-29a inhibitor, the expression of miR-29s were repressed by antagomiR-29a significantly in GT1-7 cells (Fig. 4A). However, due to the limited area of the injection, miR-29s of the whole hypothalamus were unaffected (Fig. 4B). Given that the silencing duration of antogomiRs was as long as 23 days 

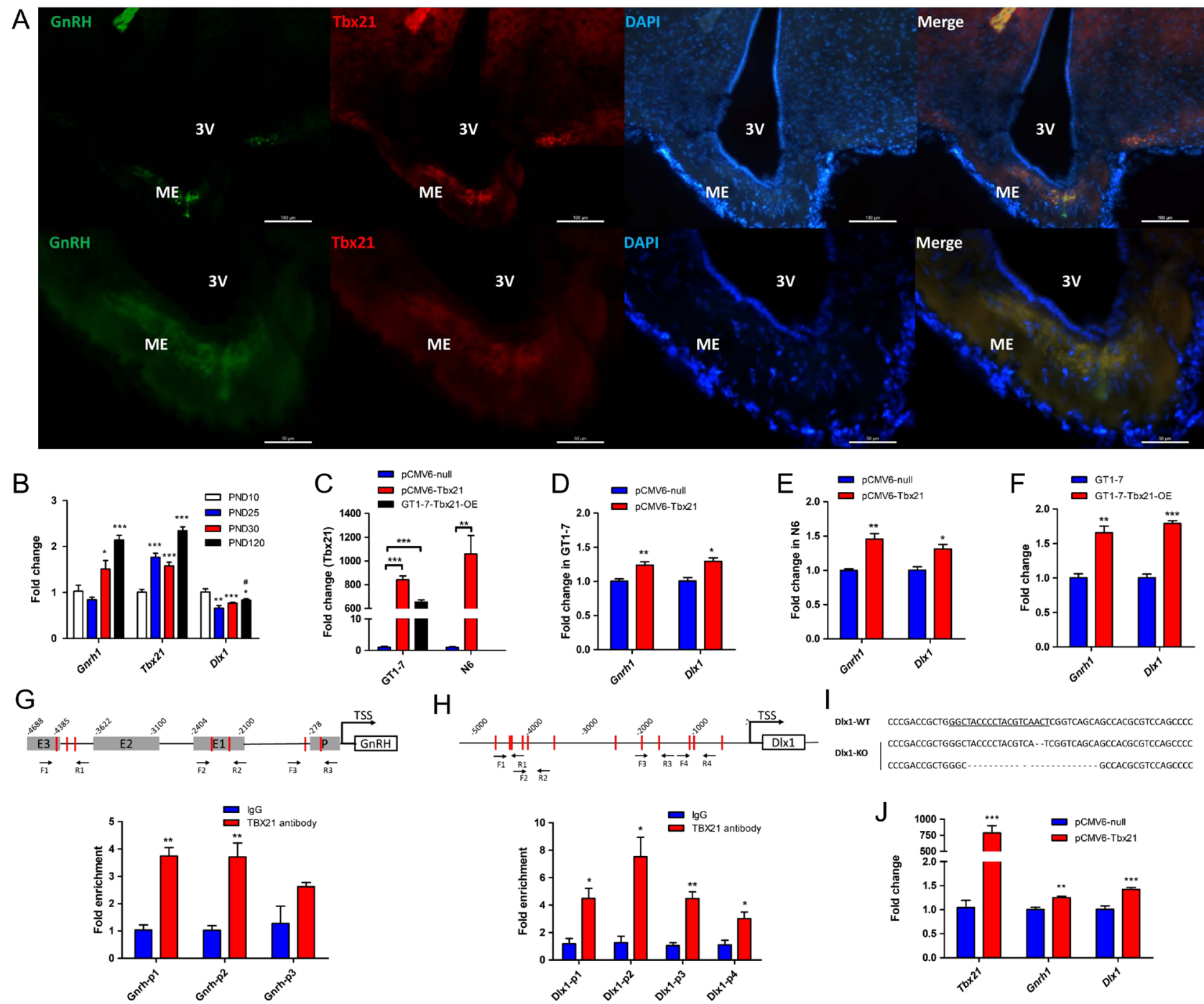

\section{Figure 3}

The regulatory role of Tbx21 in the expression of Gnrh1 both in vivo and in vitro. (A) Fluorescence micrographs of the expression of GnRH and TBX21 in the ME of female mouse. Upper panel: low magnification images of GnRH (Left), TBX21 (Central Left) and DAPI (nuclear staining; Central Right), final merge of the three signals (right), scale bar: $100 \mu \mathrm{m}$; lower panel: the higher magnification of the upper panel, scale bar: $50 \mu \mathrm{m}$. (B) The expression of Gnrh1/D/x1/Tbx21 from infants to adults in mouse hypothalamus detected by qRT-PCR. One-way ANOVA post hoc Dunnett's test, $n=6$ per group, compared with PND10, for Gnrh1 $P_{(\mathrm{PND} 25)}=0.1910, P_{(\mathrm{PND} 30)}=0.0389, P_{(\mathrm{PND} 120)}<0.0001$; for Tbx21 $P_{(\mathrm{PND} 25)}<0.0001, P_{(\mathrm{PND} 30)}=0.0002, P_{(\mathrm{PND} 120)}<0.0001 ;$ for D $1 \times 1$ $P_{(\mathrm{PND} 25)}=0.1910, P_{(\mathrm{PND} 30)}=0.0389, P_{(\mathrm{PND} 120)}<0.0001$, compared with PND25, $P_{(\mathrm{PND} 120)}=0.0190$. (C) The level of $T b x 21$ expression in pCMV-Tbx21 transiently transfected GT1-7, N6 and stably Tbx21-overexpressed GT1-7-Tbx21-OE. Unpaired two-tailed Student's $t$-test, $n=6$ per group, $P_{(\mathrm{GT} 1-7)}<0.0001$,

$P_{(\mathrm{NG})}=0.0024, P_{(\mathrm{GT1} 1-\mathrm{T} \text {-Tbx21-OE) }}<0.0001$. (D and E) The effect of transient Tbx21 overexpression on Gnrh1 and D/x1 in GT1-7 and N6. Unpaired two-tailed Student's $t$-test, $n=6$ per group, for GT1-7, $P_{(G n r h 1)}=0.0034, P_{(\mathrm{D} \mid x 1)}=0.0026$; For N6, $P_{(\mathrm{Gnrh} 1)}=0.0057, P_{(\mathrm{DI} \times 1)}=0.0202$. (F) The expression of $G n r h 1$ and $D / x 1$ in GT1-7-Tbx21-OE. Unpaired two-tailed Student's $t$-test, $n=6$ per group, $P_{(G n r h 1)}=0.0042, P_{(\mathrm{D} \mid \times 1)}=0.0003$. $(\mathrm{G}$ and $\mathrm{H})$ The distribution of putative TBX21-binding sites on the mouse Gnrh1 and D/x1 gene (upper panel) and their validation using a TBX21 chromatin immunoprecipitation assay in GT1-7. The gray squares represent enhancers and promoter of Gnrh1. The red vertical line represent putative TBX21-binding sites. The arrow indicates the location of the

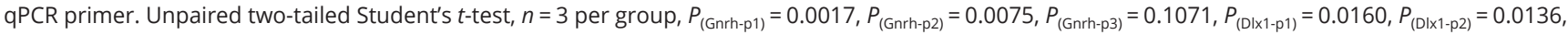
$P_{(\mathrm{D} \mid \times 1-\mathrm{p} 3)}=0.031, P_{(\mathrm{D} \mid \times 1-\mathrm{p} 4)}=0.0340$. (I) The genotype of $D / x 1$-knockout GT1-7 cell. The underlined bases are the sgRNAs recognition sites. (I) The effect of transient Tbx21-overexprssion on Gnrh1 and D/x1 in D/x1-knockout GT1-7. Unpaired two-tailed Student's $t$-test, $n=5$ per group, $P_{(\text {Tbx21) }}=0.0001$, $P_{(G n r h 1)}=0.0018, P_{(\mathrm{D} \mid x 1)}=0.0007 . * P<0.05, * \star P<0.01, * \star \star P<0.001 .3 \mathrm{~V}, 3$ rd ventricle; ME, median eminence.

after intravenous injection (Krutzfeldt et al. 2005), we carried out stereotactic brain infusions at PND15. The mice were killed at 20 days after injection, and the brain sections were made to inspect the site of action.
The signal of antagomiR-29a was concentrated near the third ventricle (Fig. 4C and Supplementary Fig. 4). Though the growth rate was similar between the antagomiR-29a3p-injected and control mice (Fig. 4D and G), https://joe.bioscientifica.com https://doi.org/10.1530/JOE-19-0082 (c) 2019 Society for Endocrinology Published by Bioscientifica Ltd. Printed in Great Britain 

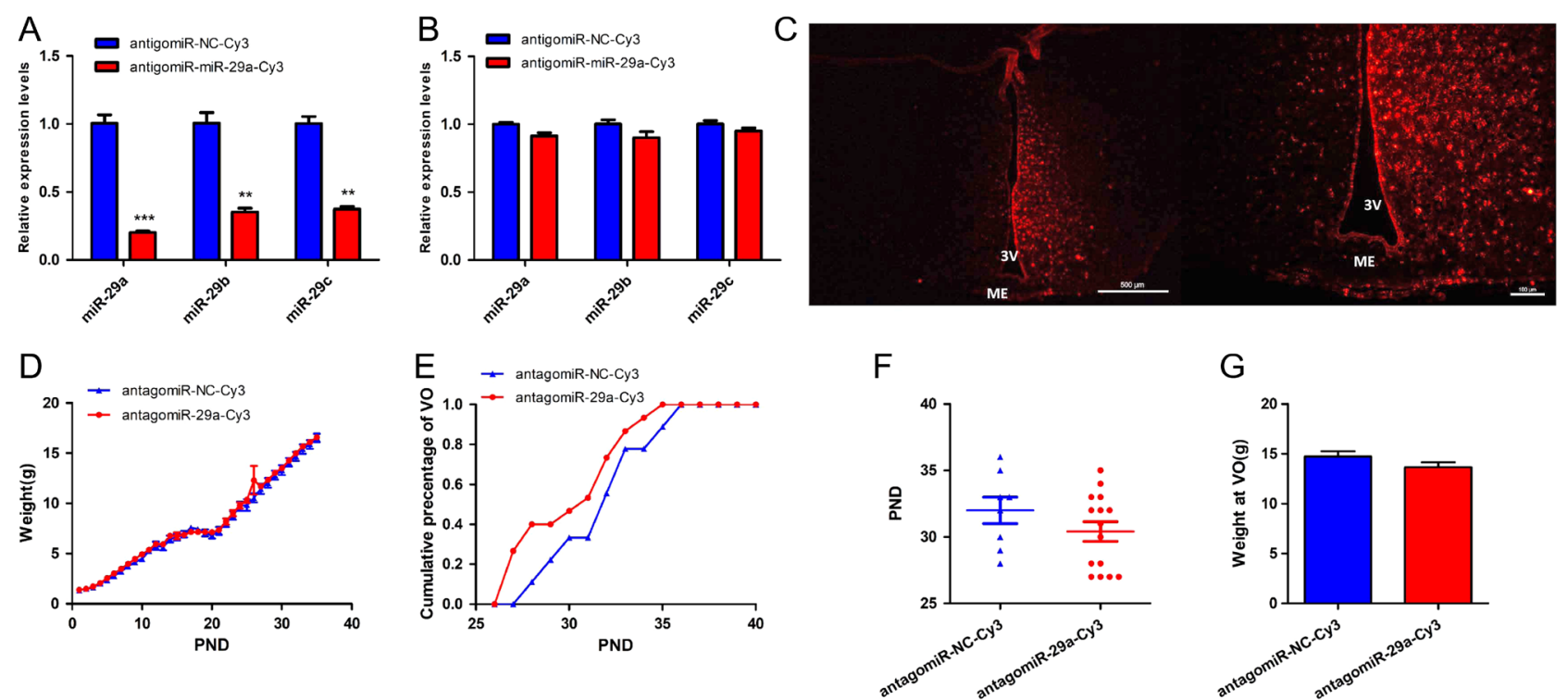

\section{Figure 4}

Effect of repression of miR-29a on the puberty onset. (A) The relative expression levels of miR-29s in GT1-7 treated with antagomiRs. Unpaired two-tailed Student's $t$-test, $n=5$ per group, $P_{(\text {mir-29a) }}=0.0009, P_{(\text {miR-29b) }}=0.0015, P_{(\text {miR-29c) }}=0.0013$. (B) The relative expression levels of miR-29s in hypothalamus treated with antagomiRs. Unpaired two-tailed Student's $t$-test, $n=6$ per group, $P_{(\text {mir-29a) }}=0.0831, P_{(\text {miR-29b) }}=0.0924, P_{(\text {miR-29c) }}=0.1985$. (C) Fluorescent photograph of brain tissue sections of antagomiRs-injected mice. 3V, third ventricle. Scale bar: $100 \mu \mathrm{m}$. (D) Growth curve of antagomiRs-injected mice. Two-way repeated-measures ANOVA, $n=8$ and 15 mice per group, $P=0.6096$. (E) Cumulative percentage of antagomiRs-injected mice over time (days) with VO. Log-rank (Mantel-Cox) test, $n=8$ and 15 mice per group, $P=0.0394$. (F) Age at vaginal opening of antagomiRs-injected mice. Mann-Whitney test, $n=8$ and 15 per group, $P=0.0610$. (G) Weight of antagomiRs-injected mice at vaginal opening. Unpaired two-tailed Student's $t$-test, $n=8$ and 15 mice per group, $P=0.1241 . * \star P<0.01, * \star * P<0.001$. A full colour version of this figure is available at https://doi.org/10.1530/JOE-19-0082.

antagomiR-29a-injected mice exhibited a precocious onset of puberty when compared with the control (Fig. 4E and F).

\section{Overexpression of $T b \times 21$ promotes the puberty onset and reproduction in mice}

Tbx21 hypothalamic ectopic expression mouse model was created by injecting viral particle carrying $T b \times 21$ and eGFP cassette into the mouse, mouse injected with the eGFP-expressing virus was used as control. The fluorescence of eGFP was detectable in brain 7 days after injection (Fig. 5A). Compared with the control mice, the Tbx21 overexpressed mice had similar growth rate but attained VO significantly earlier (Fig. 5B, C, D and E). Most of the mice with $T b \times 21$ ectopic expression showed a slight prolongation in estrus cycle (Fig. 5F), and higher serum FSH and LH levels during estrus cycles (Fig. 5G and $\mathrm{H}$ ). The assay for $\mathrm{LH}$ and $\mathrm{FSH}$ has a sensitivity of $0.28 \mathrm{ng} / \mathrm{mL}$ and $0.94 \mathrm{ng} / \mathrm{mL}$, respectively, and the intraassay coefficient of variation of the quality controls was 0.6742 (control) and 0.5665 (Tbx21) for FSH, 0.7654 (control) and 0.5093 (Tbx21) for LH. Moreover, the mice with Tbx21 overexpression had a larger first litter size (Fig. 5I), while the pregnant frequency decreased within 2 months (Fig. 5J).

\section{Discussion}

The regulation of Gnrh1 expression is of great significance for the puberty onset and reproduction in mammals. Our study discovered a novel regulation mechanism mediated by miRNA-29 family. In GT1-7 cells, both the knockout and knockdown of miR-29s resulted in the increased Gnrh1 expression which paralleled the consequence of their target $T b \times 21$ overexpression. We found that TBX21 was co-expressed with GnRH in the same increasing trend in the hypothalamus during mouse puberty onset. In vitro, TBX21 activated Gnrh1 expression as a transcription factor in both direct and indirect ways. The effect of both miR-29s and TBX21on the puberty-onset regulation was demonstrated by experiments in mouse models. Although TBX21 was predicted as an interacting protein of DLX1, our data from the Dlx1-knockout cells provided that TBX21 activated the Gnrh1 expression independent of working together with DLX1 in the form of mutual cofactors.

miR-29 family consists of four members, and they have identical 'seed' sequence and differ with each other in only a few nucleotides, so they share many identical targets. When we destroyed any one of miR-29s individually in GT1-7 cells, we could hardly find variation in 


\section{Journal of

$\mathrm{X}$ Li et al.

\section{A}
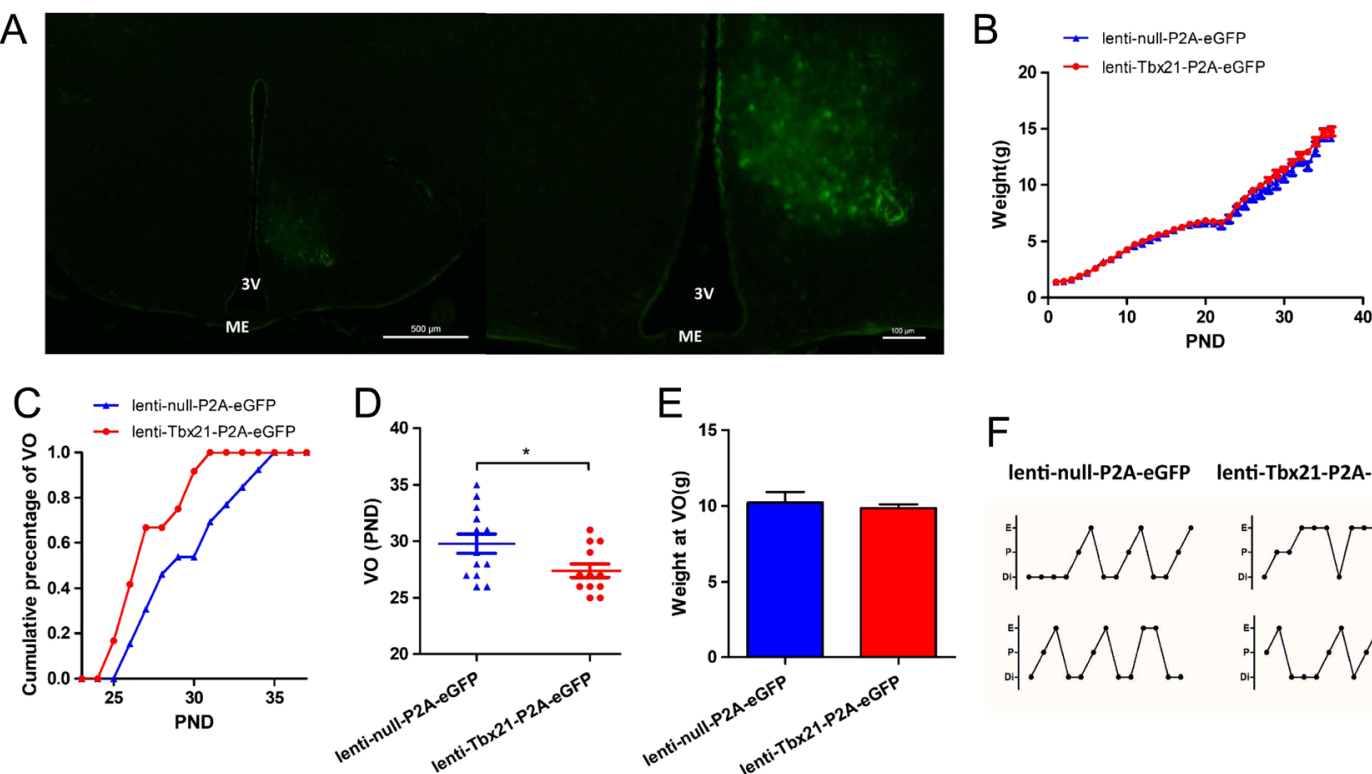

E

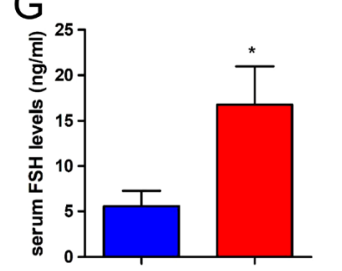

$\mathrm{H}$
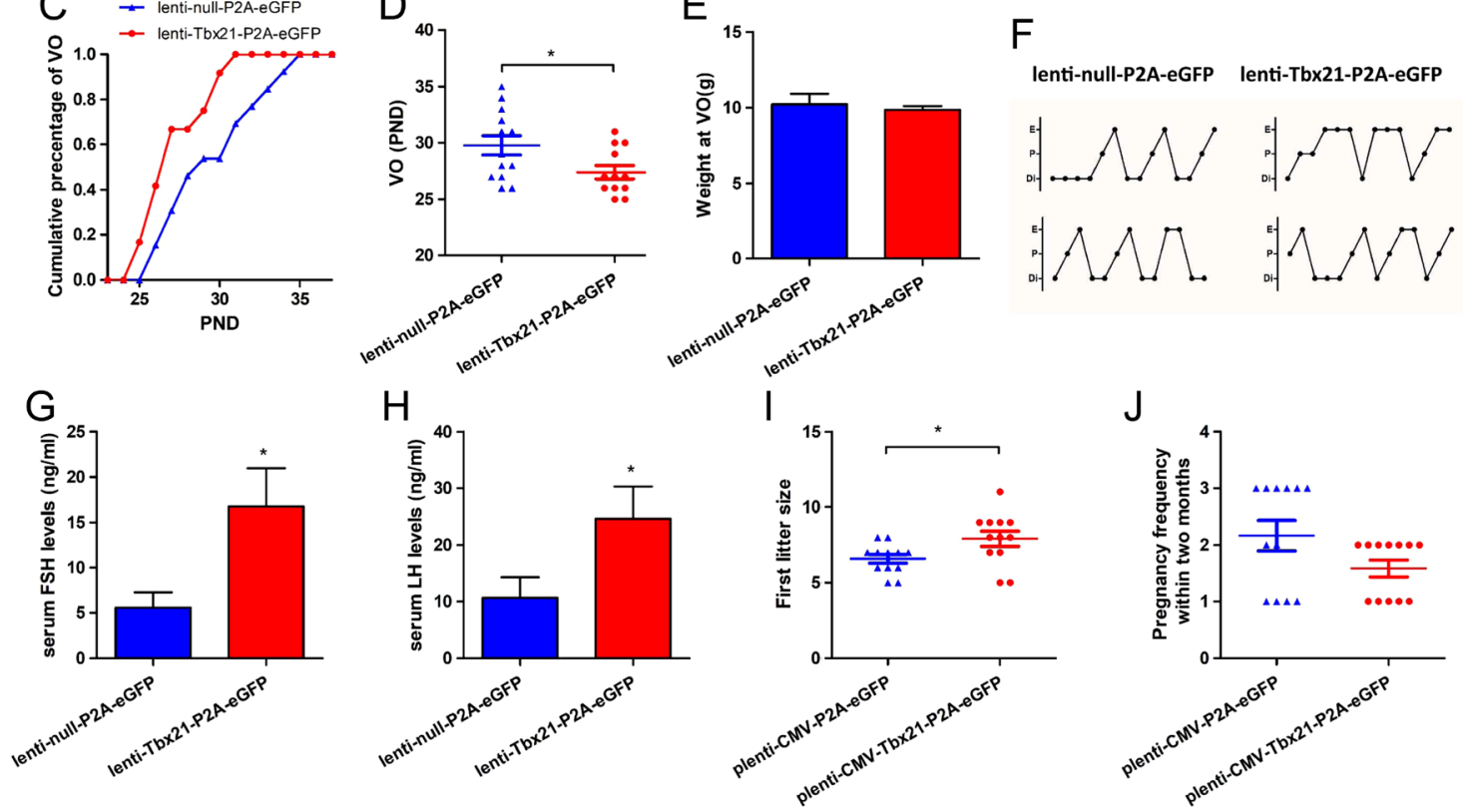

\section{Figure 5}

Effect of overexpression of Tbx21 on puberty onset and reproduction. (A) Fluorescent image of brain tissue sections of virus-injected mice. 3V, third ventricle; ME, median eminence. Scale bar: $500 \mu \mathrm{m}$ (left) and $100 \mu \mathrm{m}$ (right). (B) Growth curve of virus-injected mice. Two-way repeated-measures ANOVA, $n=13$ and 12 mice per group, $P=0.427$. (C) Cumulative percentage of virus-injected mice with vaginal opening over time (days). Log-rank (Mantel-Cox) test, $n=13$ and 12 mice per group, $P=0.0220$. (D) Age at vaginal opening of virus-injected mice. Mann-Whitney test, $n=13$ and 12 mice per group, $P=0.0423$. (E) Weight of virus-injected mice at vaginal opening. (F) Estrous cyclicity of virus-injected mice at the age of four months. Di, diestrus; $E$, estrus; $P$, proestrus. ( $\mathrm{G}$ and $\mathrm{H}$ ) Serum levels of FSH/LH during estrus of virus-injected mice. Unpaired two-tailed Student's t-test, $n=5$ mice per group,

$P_{(\mathrm{FSH})}=0.0201, P_{(\mathrm{LH})}=0.0349$. (I) Frist litter size of virus-injected mice. Unpaired two-tailed Student's $t$-test, $n=12$ mice per group, $P=0.0304$. (J) Pregnancy frequency within two months of virus injection. Unpaired two-tailed Student's $t$-test, $n=12$ mice per group, $P=0.0721$. $* P<0.05$. A full colour version of this figure is available at https://doi.org/10.1530/JOE-19-0082.

Gnrh1 expression, which was because family members usually function redundantly. The expression of any member of a miRNA family can usually rescue the family mutant phenotypes (Alvarez-Saavedra \& Horvitz 2010), while the others regulate their targets in a primarily additive fashion (Subasic et al. 2015). Benefiting from the compact distribution of the miR-29 genes in the mouse genome and the CRISPR/cas9 technology, we managed to destroy the four miR-29 genes simultaneously and observed robust increase of Gnrh1 expression in miR-29 family knockout cells. In GT1-7 cells, all miRNA-29a, miRNA-29b and miR-29c can be expressed and have binding site on the 3'UTR of Tbx21 gene. When any one of them is absent, its inhibitory effect on Tbx21 gene maybe compensated by other family members. On the other hand, the overexpression of miR29s made undetectable difference on the mRNA amount of Gnrh1 gene, which could be due to the relatively low abundance of Tbx21 in the GT1-7 cells, and the decrease of Tbx21 gene expression caused by miR-29s made limited influence on Gnrh1 expression. In contrast, Ahmed et al. found a single member of the miR-7 family, miR-7a2, was essential for normal pituitary development that mice lacking miR-7a2, not miR-7a1 or miR-7b, develop hypogonadotropic hypogonadism and infertility. They ascribed the unique character of miR-7a2 to that it is the predominant member of miR-7 family in the pituitary and that constitutive genetic ablation of miR-7a 2 was 
sufficient to cause the phenotypic variation (Ahmed et al. 2017).

The rise in the level of Gnrh1 expression in Tbx21overexpressed cells was lower than that in miR-29sknockout cells, which could be interpreted by the multiple targets of miRNAs. The product of miR-29 family distributed ubiquitously in tissues and organs, participating in a variety of biological processes, including the signal transduction, proliferation and apoptosis of neurons. The predicted target genes of miR-29 family are as many as 1051 in TargetScanMouse, a lot of them have been verified by experiments (http://mirtarbase.mbc.nctu. edu.tw/php/index.php). They are likely to differ in the expression patterns between tissues and response to the immediate cellular milieu (Slusarz \& Pulakat 2015). Studies also showed that miR-29 family synergistically regulated the same biological process, which could be supported by the fact that more than 20 target genes of miR-29s had been confirmed to be involved in the extracellular matrix synthesis (Villarreal et al. 2011). In addition to Tbx21, miR-29s may also regulate the epigenetic status of Gnrh1 gene by targeting the 3'UTR of Tet1/2/3, Dnmt3a/b, Tdg (Zhang et al. 2013b, Hysolli et al. 2016), which are the regulators of DNA methylation, including Gnrh1 (Kurian et al. 2010, 2016). Moreover, some other mechanism can be responsible for the increased expression of Gnrh1 caused by miR-29s absent as well.

We applied stereotactic brain infusion of antagomiR-29a-3p to generate the hypothalamic miR-29knockdown mouse model other than destroyed the coding genes by gene editing technology, because it could be highly laborious and time consuming to obtain the homozygous mice with four genomic loci of miR-29 family members damaged simultaneously. The cholesterol-conjugated antagomiRs can diffuse in the cells readily and have an effective window of 23 days in vivo (Krutzfeldt et al. 2005), which provides long enough period to investigate the puberty-onset phenotypes of female mice with hypothalamus locating injection. We observed the advanced VO in miR-29-knockdown female mice actually, which was consistent with the previous reports that miR-29s were promoters of female fertility. Because of the different phenotype caused by miR-29s knockdown between the female and male (Takeda \& Tanabe 2016), their effect on the fertility of male mice needs further exploring.

With the same method, we made $T b \times 21$ overexpressed mouse model by hypothalamus infusion of lentivirus carrying a Tbx21 expression cassette. The female mice of this model were affected more intensively in the puberty onset and fertility than miR-29-knockdown mice, which might result from that lentivirus integrated its genome into the host chromosome when it entered the host cell, and the foreign genes it carried could be expressed with the host genes all along.

The pulsatile release of GnRH is the result of the synergy between its stimulation and suppression signals. Messina et al. reported a miRNA switch including miR-155 and miR-200 that controlled the rise of hypothalamus GnRH production before puberty in mice (Messina et al. 2016). These results described the permitting roles of miRNAs in sexual maturation process and suggested the existence of a multilayered array of miRNAs and their target genes in the HPG axis that modulated the puberty timing and reproduction (Messina et al. 2016). Our elucidation about the repressive function of miR-29 family in Gnrh1 expression suggested multiplex roles of miRNAs in the puberty-onset regulation. Unexpectedly, during the initiation of puberty, the expression level of miR-29 rose continuously. Nevertheless, it was not the unique phenomenon that the inhibitors changed synchronously with their effector genes. For example, $\mathrm{Li}$ et al. found the expression level of miR-378 and its target gene $P G C 1 \beta$ increased simultaneously under certain conditions (Li et al. 2018). Besides, the level of Tet1/2/3, the vital DNA demethylation genes, elevated while the overall genomic methylation level decreased during the embryonic development of mouse (Jessop et al. 2018). These imply that during the period of rapid change, some mechanisms like brakes are also needed to participate in the mediation.

To conclude, our data indicated one of the mechanisms which miR-29 family takes part in the regulation of Gnrh1 expression. Transcription factor $T b \times 21$, as the target of miR-29 family, promotes Gnrh1 expression directly and indirectly, and then influences the puberty onset and reproduction of mice.

\section{Supplementary data}

This is linked to the online version of the paper at https://doi.org/10.1530/ JOE-19-0082.

\section{Declaration of interest}

The authors declare that there is no conflict of interest that could be perceived as prejudicing the impartiality of the research reported.

\section{Funding}

This study was supported by the National Nature Science Foundation of China (Grant no 31772550), the Open Project Funding of Human Phenome 
Institute (No. HUPIKF2018204), Fudan University. Open Funding Project of the State Key Laboratory of Bioreactor Engineering. The Fundamental Research Funds for the Central Universities (CUSF-DH-D-2017054).

\section{Acknowledgments}

The authors thank Prof. Zilong Qiu in Institute of Neuroscience, CAS Center for Excellence in Brain Science and Intelligence Technology, Shanghai Institutes for Biological Sciences, Chinese Academy of Sciences for his help of stereotactic brain infusions, and Prof. Xiaoying Li in Shanghai Clinical Center for Endocrine and Metabolic Diseases, Shanghai Jiaotong University for providing GT1-7 cells.

\section{References}

Ahmed K, Lapierre MP, Gasser E, Denzler R, Yang Y, Rulicke T, Kero J, Latreille M \& Stoffel M 2017 Loss of microRNA-7a2 induces hypogonadotropic hypogonadism and infertility. Journal of Clinical Investigation 127 1061-1074. (https://doi.org/10.1172/JCI90031)

Alvarez-Saavedra E \& Horvitz HR 2010 Many families of C. elegans microRNAs are not essential for development or viability. Current Biology 20 367-373. (https://doi.org/10.1016/j.cub.2009.12.051)

Amar L, Benoit C, Beaumont G, Vacher CM, Crepin D, Taouis M \& Baroin-Tourancheau A 2012 MicroRNA expression profiling of hypothalamic arcuate and paraventricular nuclei from single rats using Illumina sequencing technology. Journal of Neuroscience Methods 209 134-143. (https://doi.org/10.1016/j.jneumeth.2012.05.033)

Annis RP, Swahari V, Nakamura A, Xie AX, Hammond SM \& Deshmukh M 2016 Mature neurons dynamically restrict apoptosis via redundant premitochondrial brakes. FEBS Journal 283 4569-4582. (https://doi.org/10.1111/febs.13944)

Avendano MS, Vazquez MJ \& Tena-sempere M 2017 Disentangling puberty: novel neuroendocrine pathways and mechanisms for the control of mammalian puberty. Human Reproduction Update $\mathbf{2 3}$ 737-763. (https://doi.org/10.1093/humupd/dmx025)

Belsham DD, Cai F, Cui H, Smukler SR, Salapatek AM \& Shkreta L 2004 Generation of a phenotypic array of hypothalamic neuronal cell models to study complex neuroendocrine disorders. Endocrinology 145 393-400. (https://doi.org/10.1210/en.2003-0946)

Byers SL, Wiles MV, Dunn SL \& Taft RA 2012 Mouse estrous cycle identification tool and images. PLoS ONE 7 e35538. (https://doi. org/10.1371/journal.pone.0035538)

Chen K, Zhou YX, Li K, Qi LX, Zhang QF, Wang MC \& Xiao JH 2016 A novel three-round multiplex PCR for SNP genotyping with next generation sequencing. Analytical and Bioanalytical Chemistry $\mathbf{4 0 8}$ 4371-4377. (https://doi.org/10.1007/s00216-016-9536-6)

Ebling FJ 2005 The neuroendocrine timing of puberty. Reproduction 129 675-683. (https://doi.org/10.1530/rep.1.00367)

Garaffo G, Conte D, Provero P, Tomaiuolo D, Luo Z, Pinciroli P, Peano C, D'atri I, Gitton Y, Etzion T, et al. 2015 The Dlx5 and Foxg1 transcription factors, linked via miRNA-9 and -200, are required for the development of the olfactory and GnRH system. Molecular and Cellular Neurosciences 68 103-119. (https://doi.org/10.1016/j. mcn.2015.04.007)

Herbison AE 2016 Control of puberty onset and fertility by gonadotropinreleasing hormone neurons. Nature Reviews: Endocrinology 12 452-466. (https://doi.org/10.1038/nrendo.2016.70)

Huang PP, Brusman LE, Iyer AK, Webster NJ \& Mellon PL 2016 A novel gonadotropin-releasing hormone 1 (Gnrh1) enhancer-derived noncoding RNA regulates Gnrh1 gene expression in GnRH neuronal cell models. PLoS ONE 11 e0158597. (https://doi.org/10.1371/journal. pone.0158597)
Hysolli E, Tanaka Y, Su J, Kim KY, Zhong T, Janknecht R, Zhou XL, Geng L, Qiu C, Pan X, et al. 2016 Regulation of the DNA methylation landscape in human somatic cell reprogramming by the miR29 family. Stem Cell Reports 7 43-54. (https://doi.org/10.1016/j. stemcr.2016.05.014)

Jessop P, Ruzov A \& Gering M 2018 Developmental functions of the dynamic DNA methylome and hydroxymethylome in the mouse and zebrafish: similarities and differences. Frontiers in Cell and Developmental Biology 6 27. (https://doi.org/10.3389/fcell.2018.00027)

Keynes R \& Lumsden A 1990 Segmentation and the origin of regional diversity in the vertebrate central nervous system. Neuron 4 1-9. (https://doi.org/10.1016/0896-6273(90)90438-L)

Krol J, Loedige I \& Filipowicz W 2010 The widespread regulation of microRNA biogenesis, function and decay. Nature Reviews: Genetics 11 597-610. (https://doi.org/10.1038/nrg2843)

Krutzfeldt J, Rajewsky N, Braich R, Rajeev KG, Tuschl T, Manoharan M \& Stoffel M 2005 Silencing of microRNAs in vivo with 'antagomirs'. Nature 438 685-689. (https://doi.org/10.1038/nature04303)

Kurian JR, Keen KL \& Terasawa E 2010 Epigenetic changes coincide with in vitro primate GnRH neuronal maturation. Endocrinology 151 5359-5368. (https://doi.org/10.1210/en.2010-0555)

Kurian JR, Louis S, Keen KL, Wolfe A, Terasawa E \& Levine JE 2016 The methylcytosine dioxygenase ten-eleven translocase-2 (tet2) enables elevated GnRH gene expression and maintenance of male reproductive function. Endocrinology 157 3588-3603. (https://doi. org/10.1210/en.2016-1087)

Lee VH, Lee LT \& Chow BK 2008 Gonadotropin-releasing hormone: regulation of the GnRH gene. FEBS Journal 275 5458-5478. (https:// doi.org/10.1111/j.1742-4658.2008.06676.x)

Li Y, Jiang J, Liu W, Wang H, Zhao L, Liu S, Li P, Zhang S, Sun C, Wu Y, et al. 2018 microRNA-378 promotes autophagy and inhibits apoptosis in skeletal muscle. PNAS 115 E10849-E10858. (https://doi. org/10.1073/pnas.1803377115)

Lippi G, Steinert JR, Marczylo EL, D'oro S, Fiore R, Forsythe ID, Schratt G, Zoli M, Nicotera P \& Young KW 2011 Targeting of the Arpc3 actin nucleation factor by miR-29a/b regulates dendritic spine morphology. Journal of Cell Biology 194 889-904. (https://doi.org/10.1083/ jcb.201103006)

Luque RM, Kineman RD \& Tena-Sempere M 2007 Regulation of hypothalamic expression of KiSS-1 and GPR 54 genes by metabolic factors: analyses using mouse models and a cell line. Endocrinology 148 4601-4611. (https://doi.org/10.1210/en.2007-0500)

Messina A, Langlet F, Chachlaki K, Roa J, Rasika S, Jouy N, Gallet S, Gaytan F, Parkash J, Tena-Sempere M, et al. 2016 A microRNA switch regulates the rise in hypothalamic GnRH production before puberty. Nature Neuroscience 19 835-844. (https://doi.org/10.1038/nn.4298)

Mihalas AB \& Hevner RF 2017 Control of neuronal development by T-box genes in the brain. Current Topics in Developmental Biology 122 279-312. (https://doi.org/10.1016/bs.ctdb.2016.08.001)

Omariba G, Tong L, Wang M, Li K, Zhou Y \& Xiao J 2018 Characterization of the dynamic change of microRNA expression in mice hypothalamus during the time of female puberty. Genes and Genomics 40 295-304. (https://doi.org/10.1007/s13258-017-0633-5)

Rajman M \& Schratt G 2017 MicroRNAs in neural development: from master regulators to fine-tuners. Development 144 2310-2322. (https:// doi.org/10.1242/dev.144337)

Ravasi T, Suzuki H, Cannistraci CV, Katayama S, Bajic VB, Tan K, Akalin A, Schmeier S, Kanamori-Katayama M, Bertin N, et al. 2010 An atlas of combinatorial transcriptional regulation in mouse and man. Cell 140 744-752. (https://doi.org/10.1016/j.cell.2010.01.044)

Ripa R, Dolfi L, Terrigno M, Pandolfini L, Savino A, Arcucci V, Groth M, Terzibasi Tozzini E, Baumgart M \& Cellerino A 2017 MicroRNA miR-29 controls a compensatory response to limit neuronal iron accumulation during adult life and aging. BMC Biology 15 9. (https:// doi.org/10.1186/s12915-017-0354-x) https://joe.bioscientifica.com https://doi.org/10.1530/JOE-19-0082 (c) 2019 Society for Endocrinology Published by Bioscientifica Ltd.
Printed in Great Britain 
Saba R \& Schratt GM 2010 MicroRNAs in neuronal development, function and dysfunction. Brain Research 1338 3-13. (https://doi. org/10.1016/j.brainres.2010.03.107)

Slusarz A \& Pulakat L 2015 The two faces of miR-29. Journal of Cardiovascular Medicine 16 480-490. (https://doi.org/10.2459/ JCM.0000000000000246)

Steiner DF, Thomas MF, Hu JK, Yang Z, Babiarz JE, Allen CD, Matloubian M, Blelloch R \& Ansel KM 2011 MicroRNA-29 regulates T-box transcription factors and interferon-gamma production in helper T cells. Immunity 35 169-181. (https://doi.org/10.1016/j. immuni.2011.07.009)

Subasic D, Brummer A, Wu Y, Pinto SM, Imig J, Keller M, Jovanovic M, Lightfoot HL, Nasso S, Goetze S, et al. 2015 Cooperative target mRNA destabilization and translation inhibition by miR-58 microRNA family in C. elegans. Genome Research 25 1680-1691. (https://doi. org/10.1101/gr.183160.114)

Takeda T \& Tanabe H 2016 Lifespan and reproduction in brainspecific miR-29-knockdown mouse. Biochemical and Biophysical Research Communications 471 454-458. (https://doi.org/10.1016/j. bbrc.2016.02.055)
Tong L, Xue H, Xiong L, Xiao J \& Zhou Y 2015 Improved RT-PCR assay to quantitate the pri-, pre-, and mature microRNAs with higher efficiency and accuracy. Molecular Biotechnology 57 939-946. (https:// doi.org/10.1007/s12033-015-9885-y)

Villarreal G, Jr, Oh DJ, Kang MH \& Rhee DJ 2011 Coordinated regulation of extracellular matrix synthesis by the microRNA-29 family in the trabecular meshwork. Investigative Ophthalmology and Visual Science 52 3391-3397. (https://doi.org/10.1167/iovs.10-6165)

Zhang L, Cai Z, Wei S, Zhou H, Zhou H, Jiang X \& Xu N 2013a MicroRNA expression profiling of the porcine developing hypothalamus and pituitary tissue. International Journal of Molecular Sciences 14 20326-20339. (https://doi.org/10.3390/ijms141020326)

Zhang P, Huang B, Xu X \& Sessa WC 2013b Ten-eleven translocation (Tet) and thymine DNA glycosylase (TDG), components of the demethylation pathway, are direct targets of miRNA-29a. Biochemical and Biophysical Research Communications 437 368-373. (https://doi. org/10.1016/j.bbrc.2013.06.082)

Zhou Y, Tong L, Wang M, Chang X, Wang S, Li K \& Xiao J 2018 MiR505-3p is a repressor of the puberty onset in female mice. Journal of Endocrinology 240 379-392. (https://doi.org/10.1530/JOE-18-0533)

Received in final form 17 June 2019

Accepted 28 June 2019

Accepted Preprint published online 28 June 2019 (c) 2019 Society for Endocrinology Published by Bioscientifica Ltd. 